\title{
THE COMING RISE IN RESIDENTIAL INFLATION
}

\author{
Marijn A. Bolhuis \\ Judd N. L. Cramer \\ Lawrence H. Summers \\ Working Paper 29795 \\ http://www.nber.org/papers/w29795
NATIONAL BUREAU OF ECONOMIC RESEARCH
1050 Massachusetts Avenue
Cambridge, MA 02138
February 2022

We thank Ed Glaeser for comments. The views expressed herein are those of the authors and do not necessarily reflect the views of the National Bureau of Economic Research, IMF, its Executive Board, or IMF management.

NBER working papers are circulated for discussion and comment purposes. They have not been peer-reviewed or been subject to the review by the NBER Board of Directors that accompanies official NBER publications.

(C) 2022 by Marijn A. Bolhuis, Judd N. L. Cramer, and Lawrence H. Summers. All rights reserved. Short sections of text, not to exceed two paragraphs, may be quoted without explicit permission provided that full credit, including $(\odot$ notice, is given to the source. 
The Coming Rise in Residential Inflation

Marijn A. Bolhuis, Judd N. L. Cramer, and Lawrence H. Summers

NBER Working Paper No. 29795

February 2022

JEL No. E01,E31,E37,R21,R31

\section{ABSTRACT}

We study how the recent run-up in housing and rental prices affects the outlook for inflation in the United States. Housing held down overall inflation in 2021. Despite record growth in private market-based measures of home prices and rents, government measured residential services inflation was only four percent for the twelve months ending in January 2022. After explaining the mechanical cause for this divergence, we estimate that, if past relationships hold, the residential inflation components of the CPI and PCE are likely to move close to seven percent during 2022. These findings imply that housing will make a significant contribution to overall inflation in 2022, ranging from one percentage point for headline PCE to 2.6 percentage points for core CPI. We expect residential inflation to remain elevated in 2023.

Marijn A. Bolhuis

International Monetary Fund

mbolhuis@imf.org

Judd N. L. Cramer

Independent Researcher

judd.cramer@gmail.com
Lawrence H. Summers

Harvard Kennedy School of Government

79 JFK Street

Cambridge, MA 02138

and NBER

lhs@harvard.edu 


\section{Section 1: Introduction}

Inflation has been a matter of major concern in the US in recent months. Many believe inflation has been substantially elevated by a range of transient factors associated with bottlenecks. The point has also been made that rapid inflation reflects the relative strength of goods compared to services. This note highlights that residential services inflation operates in the opposite direction with the likelihood of a significant acceleration in 2022 even if there is no change in underlying inflation. The way that housing inflation is measured - as the average price growth across all housing occupants, not as the average price increase faced by someone looking for housing today-ensures that past developments in the housing market will result in an increase in recorded housing inflation in 2022.

A few basic statistics suggest the importance of residential services to the overall inflation process. The two largest components of residential services, owners' equivalent rent of residence (OER) and rent of primary residence, combine to range from about 15 percent of the Personal Consumption Expenditure Price (PCE) Index to almost 40 percent of the Consumer Price Index (CPI) core measure, which strips away volatile energy and food prices. ${ }^{1}$ This represents roughly half of the services component of CPI.

Measured residential services inflation was only 4.1 percent in the twelve months ending in January 2022 for OER, and 3.8 percent for the less significant rental housing component over the same period. These figures seem almost incommensurate with private sector estimates of the current change in the cost of living for homeowners and renters. Over the same period, home prices

\footnotetext{
${ }^{1}$ PCE weights are the nominal consumption shares found in NIPA table 2.4.5.U, which oscillate quarterly. CPI weights were updated to match consumer expenditure data from 2019-2020. See section 2 for more information on how the indices differ and a recent discussion of similar issues in work by the Council of Economic Advisers (Bernstein et al., 2021).
} 
have jumped by 19.9 percent according to Zillow. The Zillow Observed Rent Index has increased 14.9 percent, and the CoreLogic Single-Family Rent Index, likely to be a particularly good leading indicator for OER, had risen by 12 percent in December (Figure 1). ${ }^{2}$

\section{Figure 1: Growth in Measures of Housing Costs, latest releases}

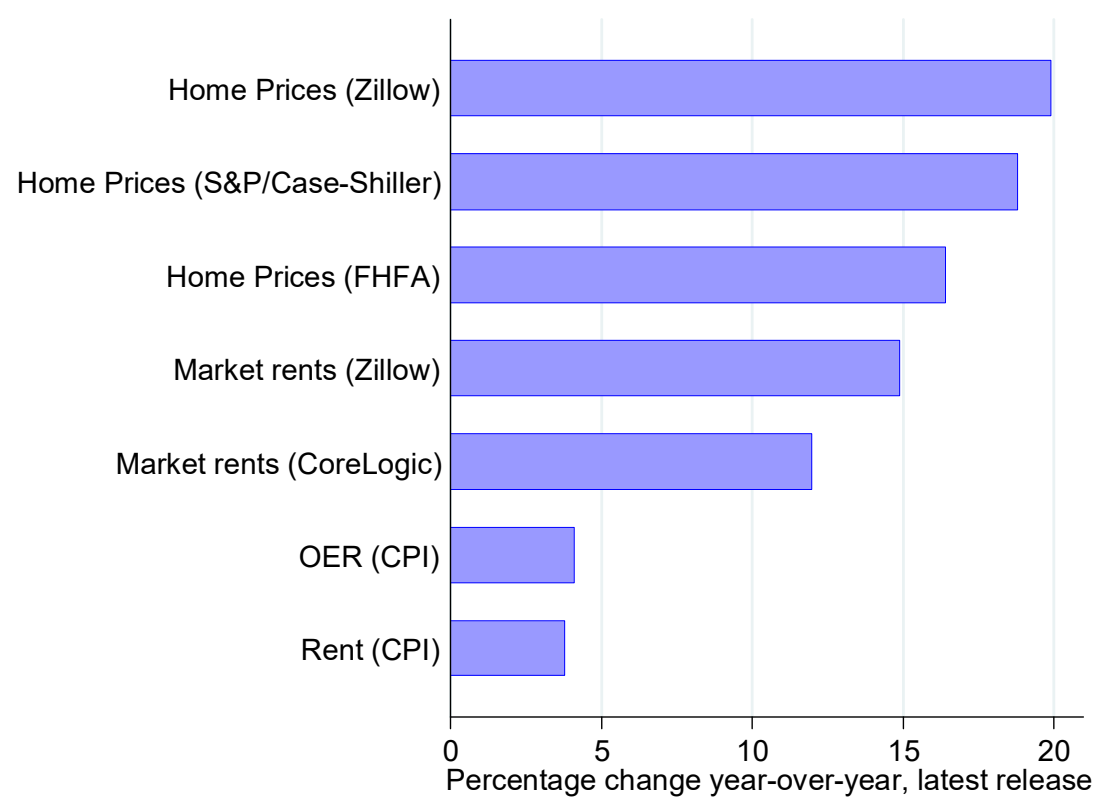

Sources: Zillow Home Value Index, S\&P Case-Shiller Home Price Index, FHFA House Price Index, CoreLogic Single-Family Rent Index, Zillow Observed Rent Index, CPI Owner's Equivalent Rent of Residences, CPI Rent of Primary Residence.

Notes: Figure plots latest data release of series, expressed in percentage change relative to 12 months earlier.

S\&P/Case-Shiller from November 2021, FHFA from Q3 2021, CoreLogic from December 2021. Other series from January 2022.

This raises the question of whether a significant increase in housing inflation is ahead of us, even apart from whatever happens to market-based indicators of rents and prices going forward. The objective of this note is to provide rough estimates for the housing component of inflation in the near term. If past relationships hold into 2022, we conclude that housing inflation is likely to move

\footnotetext{
${ }^{2}$ Glaeser and Gyourko (2009) show that the rental stock and owner-occupied stock of housing differ significantly, with single-family homes more prevalent amongst owner-occupied units.
} 
to between 6.5 percent and seven percent and make a significant contribution to overall inflation in 2022, ranging from one percentage point for PCE, to 2.6 percentage points for core CPI. Our estimates imply housing's contribution to overall inflation would be between 0.4 and 1.1 percentage points higher in 2022 compared to 2021, depending on the choice of index. We believe that our estimates are relatively robust due to their stability irrespective of data series choices or forecasting techniques.

The rest of this note is structured as follows. Section 2 reviews the methodology used by the Bureau of Labor Statistics (BLS) and the Bureau of Economic Analysis (BEA), informing housing price indices and suggests that it is natural to expect that they will lag private market-based indicators. Section 3 describes the data we employ and different statistical models for forecasting housing inflation. Section 4 presents our forecasts of housing's contribution to each of the major indices used in tracking consumer prices. Section 5 offers some concluding observations. 


\section{Section 2: Measuring the cost of housing}

\section{CPI vs. PCE}

The Bureau of Economic Analysis (BEA), which produces the Personal Consumption Expenditure Price (PCE) Index, and the Bureau of Labor Statistics (BLS), which produces the Consumer Price Index (CPI), assign significantly different weights to housing. ${ }^{3}$ Table 1 shows that housing receives substantially higher weight in the CPI than in the PCE for both headline and core. This means our residential services forecasts will imply different trajectories for overall inflation depending on the index.

\section{Table 1. Differences in weight shares in housing PCE vs. CPI, percent}

\begin{tabular}{lcccc} 
& \multicolumn{4}{c}{ Series } \\
\cline { 2 - 5 } Component & CPI & Core CPI & PCE & Core PCE \\
\hline Owners' Equivalent Rent & 23.6 & 29.9 & 11.2 & 12.8 \\
Rent & 7.4 & 9.6 & 3.6 & 4.1 \\
& & & & \\
\hline
\end{tabular}

Sources: Bureau of Labor Statistics, Bureau of Economic Analysis, authors' calculations Notes: PCE weights will change with new releases and revisions.

This "weight" effect is the result of the BLS and BEA sourcing consumer expenditure data-which are used to weight the price changes of items - from different surveys and for using different definitions of housing components. ${ }^{4}$ In the CPI, for example, weights for owners' equivalent rents

\footnotetext{
${ }^{3}$ Throughout this note, housing includes only owners' equivalent rent and rent.

${ }^{4}$ See Blair (2015) for a complete discussion. The literature decomposes differences between CPI and PCE into four pieces: weight, scope, formula and 'other.' "Weight" is the largest factor as mentioned in the text. "Scope" considers the differing targets of the surveys - all personal consumption for all people in the PCE and out-of-pocket expenditures for urban dwellers in the CPI. This tends to lower the weight on housing in the CPI. The formula effect is the result of the PCE's formula producing a chain-type price index whereas the CPI measures the price of a fixed basket of goods. This will result in the CPI tending to overstate inflation as consumers generally substitute away
} 
are gleaned from the Current Expenditure Survey of households. Homeowners are asked "if someone were to rent your home today, how much do you think it would rent for monthly, unfurnished and without utilities?" In the PCE, the share of income used on housing for owneroccupiers is estimated from Personal Consumption Expenditure data in the National Income and Product Accounts and used to weight the inflation measure. ${ }^{6}$ This procedure leads to the CPI weights for owner's equivalent rent being significantly higher. ${ }^{7}$

The housing components of both series, while having differing weights, use the BLS's CPI price measure for inflation. ${ }^{8}$ This is not often the case as the PCE and CPI generally use divergent methodologies to capture different economic activities. ${ }^{9}$ Assessing rent changes and especially changes in owners' equivalent rent is a difficult problem and the BLS methodology creates an accurate but more backward-looking measure, which we explain below.

\section{Calculating Rent Indices}

Unlike milk, rent is not something a consumer encounters a price for daily. ${ }^{10}$ Most renters enter into long-term leases with terms fixed for a period, generally six to twelve months. ${ }^{11}$ Even if the spot price of rent jumps, as it has recently, not all renters has to pay the increase immediately as

from goods that have become relatively more expensive. While this will have effects on the indices writ large, it is not a major concern for the housing component itself. 'Other' is the catch-all term for other differences, including seasonal adjustments and different revision schedules, along with a few other factors that have small impacts for housing, but can result in small deviations across the series.

${ }^{5}$ In addition, in the CPI, housing expenditures include mortgage interest and charges, property taxes, and maintenance, repair, insurance, and other expenses, see (Passero et al., 2014).

${ }^{6}$ See Garner et al. (2006) for a further breakdown of procedures.

${ }^{7}$ For a more complete, recent discussion of how PCE differs from CPI for housing and other categories, most notably healthcare, see Johnson (2017).

${ }^{8}$ See Rassier et al. (2021) for a discussion of future innovations in housing measurement from the BEA.

${ }^{9}$ McCully et al. (2007) shows how "rent of shelter" explained a large amount of the 0.4 percentage point difference in growth rates between PCE and CPI between 2002 and mid-2007 and compares this to other categories.

${ }^{10}$ Roughly 36 percent of households are headed by a renter, De Silver (2021)

${ }^{11}$ When the Census ran a survey of property owners and managers in 1995-1996, they found that for single family homes where rent was paid: $36.2 \%$ had leases that were exactly a year; $3.3 \%$ had leases of more than a year, $33.0 \%$ had leases of less than one year; and $27.5 \%$ had no lease at all. 
many have their rates fixed for the lease period. The BLS recognizes this general lack of change so rather than ask each of the approximately 50,000 rental units in their sample for rent prices each month, they divide the households into six panels with each asked their rental rates six months apart.1 Panel 1 receives the survey in January and July, Panel 2 in February and August, and so forth. When these data are collected, they are adjusted for various properties of the unit and area to create a harmonized measure for the month's panel relative to its previous measure. The CPI index, however, is designed to calculate the monthly change rather than the six-month change, so the BLS uses the sixth-root of this derived measure to calculated the yield a one-month relative price:

$$
R E L_{t-1, t, a}=\sqrt[6]{R E L_{t-6, t, a}}
$$

A few points about the index are notable. As opposed to the real-time data we employ in section 3, the BLS measure is a more backward-looking indicator. Rather than measuring the spot pricefocusing on new leases signed - the index amalgamates all existing leases. This methodology produces a weighted average of the last year in the rental market without explicitly giving observers the weights. Verbrugge (2008) shows how this may over-smooth the series. In periods of particularly strong rental growth, as we have been experiencing, this will serve to dampen the increase. ${ }^{12}$ As we will show in more detail later, this produces a quasi-mechanical lagged correlation with real-time prices for both housing and rentals. Dolmas \& Zhou (2021) documents that historically the BLS measure of 12-month change in rental prices is more strongly correlated

\footnotetext{
${ }^{12}$ It may follow from a similar argument that this methodology could prolong the increase once the market has stabilized.
} 
with the 12-month change in housing prices observed 16 months earlier than any more recent reading. ${ }^{13}$

\section{Owners' Equivalent Rent}

Housing plays multiple roles for American homeowners. On the one hand, it is the largest fixed investment that most Americans make in their lives. ${ }^{14}$ On the other hand, it provides a service, shelter, that is consumed daily. The BLS has the difficult task of isolating the consumption component and measuring its price change over time. Since this price is not observed, the BLS uses statistical techniques to infer OER using rental prices for similar units in the area. ${ }^{15}$ In particular, the estimated average OER value is determined by a linear regression of imputed rents on property value, income, and number of rooms from the Consumer Expenditure Survey. ${ }^{16}$ Once again, this procedure is done for all units, not just newly signed leases or newly purchased houses. to the rent index, and for the same reasons, the estimated OER will therefore lag spot prices. This does not imply that the procedure is incorrect in any way-it answers exactly the question the statistical agencies want to address - but it does suggest that there might be more information about the future trajectory of measured housing inflation outside these indices.

\footnotetext{
${ }^{13}$ This aligns with similar work by Brescia (2021) who used housing price changes five quarters earlier to make inflation projections.

${ }^{14}$ This has been the case throughout American history. See, for example, Shelton (1966).

${ }^{15}$ For a recent discussion of BEA's methods and how they might be modified and integrated with Zillow data see Gindelsky et al. (2019).

${ }^{16}$ For complete details, see Chapter 17 of the BLS handbook of methods. The linear regression coefficients are then applied to decennial census values for the same independent variables to estimate the average owners' equivalent rent for each segment via the nonlinear regression

$$
\text { OER }=\beta o+\left(\beta_{1} \times \text { propval }\right)+\left(\beta_{2} \times \text { propval }^{2}\right)+\left(\beta_{3} \times \text { income }\right)+\left(\beta_{4} \times \text { rooms }\right),
$$

where $O E R$ is the predicted value that the home would rent for, propval is the market value of the home, income is the income of the consumer unit, and rooms is the number of rooms in the house. The BLS repeats this procedure across different geographic areas. After the modelling process, CPI weights are then determined by surveys of homeowners.
} 


\section{Section 3: Data and Forecasting Model}

\section{Data}

We use private sector data on rents and home prices to make more accurate forecasts of the government measures. These private sector data series lead the official residential inflation components from the CPI and PCE. To track market rents, we use two series. Our preferred measure is the CoreLogic Single-Family Rent Index, which starts in 2005. We also include the Zillow Observed Rent Index (ZORI), available from 2014, which leverages the company's large database of rental prices to track changes in asking prices over time for all homes. ${ }^{17}$

To measure the movements in home prices, we use the Zillow Home Value Index (ZHVI). This index reflects the typical value for homes in the 35 th to 65 th percentile range across the US for all home types. The index starts in January 2000. We also use the S\&P/Case-Shiller U.S. National Home Price Index which has less coverage than the ZHVI but is available since 1987.

Historically, the year-over-year growth in home prices and market rents have been powerful leading indicators for OER inflation and rent inflation. Throughout this note, we focus on yearover-year changes to avoid the difficulties of seasonality in housing data. Figure 2 summarizes the relationships between these variables in our dataset. Year-over-year growth in OER, either in the CPI or PCE, correlates most strongly with the 16- and 12-month lags of home prices and private sector rents, respectively. Growth in the rent component of the CPI and PCE correlate most strongly with the 18- and 13-month lags of home prices and private sector rents. The elasticity of OER and rent with respect to in private sector rents has been about 0.5 , on average. Due to the

\footnotetext{
${ }^{17}$ This follows from the work of Ambrose et al. (2015) which constructs a measure of recently turned over apartments. The authors document large, sustained deviations from the official measures.
} 
volatility of the housing market, the elasticity of OER and rent with respect to home prices is considerably smaller, at about 0.13 .

\section{Figure 2: Private Sector Data Lead CPI Housing Components}

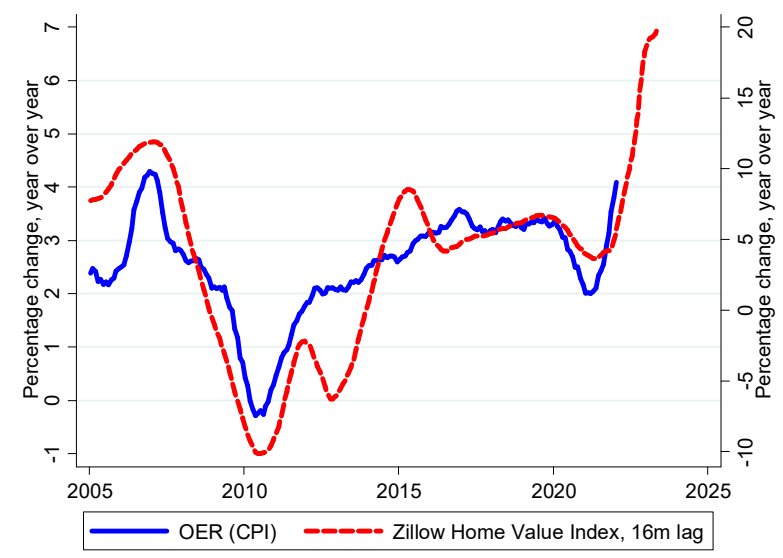

(a)

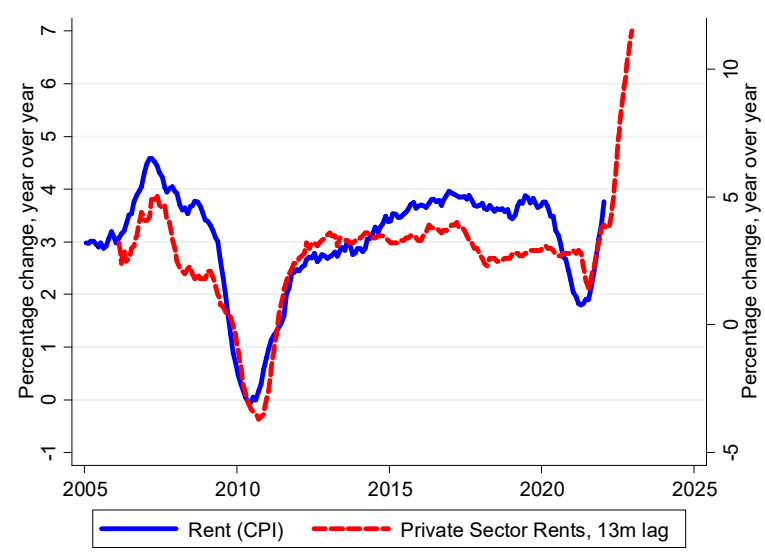

(b)

Sources: Private sector rent data from CoreLogic Single-Family Rent Index. Home prices from Zillow Home Value Index.

Notes: Figure (a) plots the year-over-year percentage change in OER against the 16 months lag of the year-overyear percentage change in home prices. Figure (b) plots the year-over-year percentage change in CPI rent against the 16 months lag of the year-over-year percentage change in private sector rents.

\section{Forecasting Model}

We use the elastic net regression method for our forecasts. ${ }^{18}$ The elastic net is a machine learning algorithm that performs regularization and variable selection on linear models (Zou \& Hastie, 2005). It is a hybrid of the commonly used lasso (Tibshirani, 1996) and ridge (Hoerl \& Kennard,

${ }^{18}$ All findings are robust to using OLS. Results available upon request. 
1970) regression methods. ${ }^{19}$ In recent years, the elastic net has become a popular forecasting method for macroeconomic series (Bai \& Ng, 2008; Eickmeier \& Ng, 2011; Cepni et al., 2019; Richardson et al., 2021). The lasso and elastic net tend to have a better out-of-sample forecasting performance than traditional regression methods, such as OLS, because they reduce overfitting on historical data by shrinking coefficients. Compared to the lasso, the elastic net is particularly suited for time-series settings with many potential predictors and limited observations. The elastic net retains the interpretability of OLS and lasso, in contrast to commonly used models that rely on dimension reduction techniques, such as dynamic factor models (Stock \& Watson, 2011).

Our main specification includes two years of lags in the year-over-year growth rate of the dependent variable, home prices, and private sector rents from CoreLogic. We impute the CoreLogic series for January 2023 using the Zillow rent series. For more than one month ahead forecasts, we drop lags for which we do not have data.

\footnotetext{
${ }^{19}$ In particular, with $J$ predictors and $T$ time periods, the vector of coefficients of the elastic net is given by $\beta=$ $\left.\arg \min \left[\sum_{t=1}^{T}\left(y_{t}-\beta_{0}-\sum_{j=1}^{J} x_{j t} \beta_{j}\right)+\lambda \sum_{j=1}^{J} \alpha \beta_{j}^{2}+(1-\alpha)\left|\beta_{j}\right|\right)\right]$, where $\alpha$ and $\lambda$ are hyperparameters estimated using cross-validation.
} 


\section{Section 4: Results}

\section{Owners' Equivalent Rent}

We start by forecasting the largest component of housing inflation, owners' equivalent rent. We train the model on all available monthly data from 2005 to January 2022. Table 2 summarizes the end-of-year 2022 and 2023 forecasts and relates them to current data. We provide monthly forecasts in the Appendix.

Our forecasts suggest OER inflation will accelerate in 2022. The model projects a steady increase in the first half of the year, peaking in the second half with a forecast for OER CPI inflation of 6.3 percent, and OER PCE inflation of 6.4 percent in December (Figure 3). Variable selection of the elastic net suggests that these increases are mainly driven by the spike in private sector rents in recent months.

Our projections suggest that OER will remain elevated in 2023. After peaking in late 2022, the model forecasts that OER will remain above six percent in early 2023. The forecast declines to five percent in December 2023.

The model shows good in- and out-of-sample forecasting performance. To evaluate the model, we train it on data from 2005 to 2013, and then compare the model's historical performance at forecasting rent inflation for one to twelve months. We do this on a rolling basis from 2014 to 2021, adding more data as we move along. For next month forecasts, the model's forecasts deviate from the actual rate of OER inflation by only 0.06 percentage points on average. When forecasting twelve months ahead, the model misses the actual rate of OER inflation by only an average of 0.34 percentage points. We plot the historical out-of-sample performance in the Appendix. 
Figure 3: Projected OER and Rent
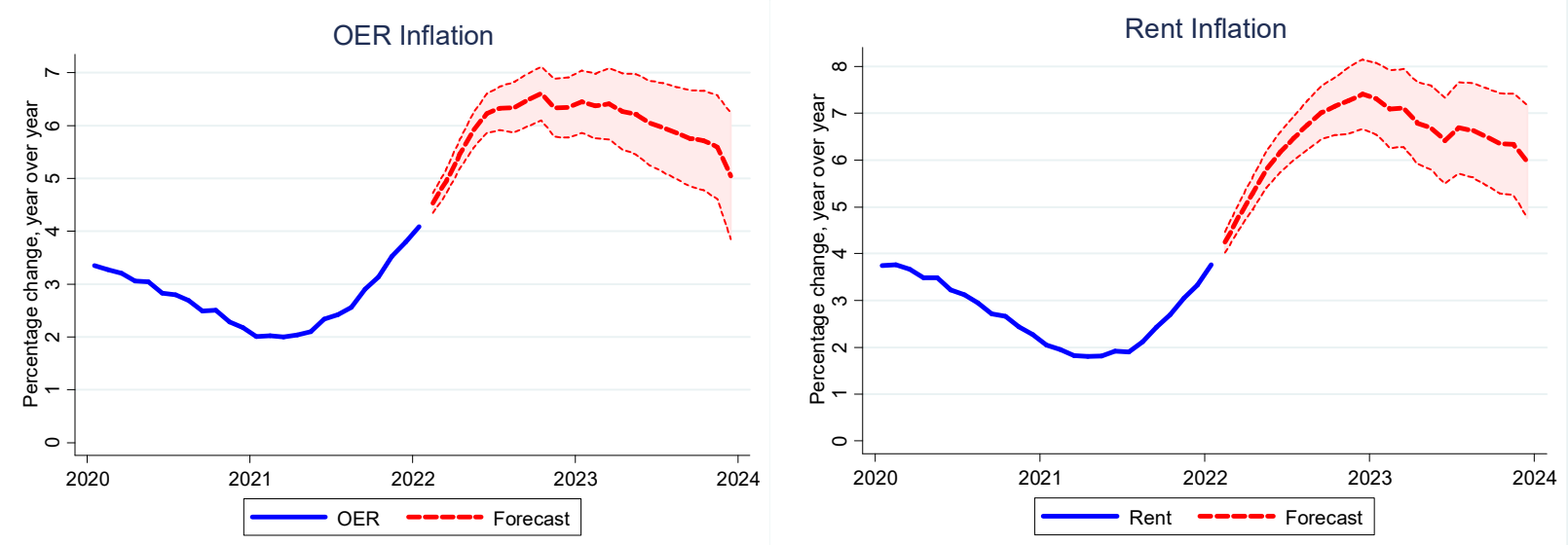

Sources: Bureau of Labor Statistics. Private sector rent data from CoreLogic Single-Family Rent Index. Home prices from Zillow Home Value Index. Authors' calculations.

Notes: Forecast model is an elastic net using 24 months of lags in the year-over-year growth rates of the dependent variable and 24 months of lags in the year-over-year growth rate of the Zillow Home Value Index and the CoreLogic Single-Family Rent Index. Dotted lines are 95\% confidence intervals based on in-sample forecast errors. We show forecasts for CPI components only.

Table 2. Recent Housing Inflation Data and Forecasts for Dec. 2022 and Dec. 2023

\begin{tabular}{ccccc|} 
& \multicolumn{4}{c}{ Percent change, year-over-year } \\
\cline { 2 - 5 } Component & Dec. 2019 & Dec. 2021 & Dec. 2022 (forecast) & Dec. 2023 (forecast) \\
\hline OER & 3.3 & 3.8 & 6.3 & 5.0 \\
Rent & 3.7 & 3.3 & 7.4 & 6.0 \\
Housing & 3.4 & 3.7 & 6.6 & 5.3 \\
\hline
\end{tabular}

Sources: Bureau of Labor Statistics, Bureau of Economic Analysis, authors' calculations

Notes: Forecast model is an elastic net using 24 months of lags in the year-over-year growth rates of the dependent variable and 24 months of lags in the year-over-year growth rate of the Zillow Home Value Index and the CoreLogic Single-Family Rent Index. We use weights from Dolmas \& Zhou (2021). We present forecasts for CPI components only. Housing includes only owners' equivalent rent and rent. 


\section{Rent}

Our forecasts of rent inflation show a similar picture, implying a sharp acceleration in 2022. Again, our main specification includes two years of lags in the year-over-year growth rate of the dependent variable, home prices, and private sector rents. We project that the rate of rent inflation will increase by about one third of a percentage point each month, reaching 7.4 percent in December 2022 for the CPI and 7.3 percent for the PCE. Variable selection by the elastic net implies that higher private sector rents are driving the forecast. We forecast that rent inflation will remain high in 2023, declining slightly to six percent by December.

\section{Contributions to headline and core inflation}

Our forecasts suggest that housing will form a significant contributor to overall inflation in 2022. To calculate the contribution of housing inflation to core and headline inflation, we weighed our forecasts using weights of each component in the CPI and PCE. Table 3 and Figure 4 summarize these contributions over time. Our forecasts imply that rent and OER will add 2.6 percentage points to core CPI in December 2022. This would be the largest contribution of housing to core CPI since 1986. The contribution of housing to core inflation is less pronounced for the PCE price index. Our forecasts imply that housing will add 1.1 percentage points to core PCE by the end of 2022. This difference reflects the lower weight of housing in the PCE basket, which covers a wider range of items than the CPI. Overall, these estimates suggest that the contribution of rising housing costs to core inflation will increase by 50 to 110 basis points compared to December 2021. For 2023, the contribution of housing will remain above current levels. This means that total services, of which residential services makes up roughly half in the CPI, would only return to two percent if all other services experienced significant deflation. In the PCE, where residential services make 
up around a quarter of total services, less of a marked decline in other services is required for a return to target, but housing will still present a headwind against easing inflation as summarized in Table 3.

Table 3. Contribution of Housing to Services, Core, and Headline Inflation

\begin{tabular}{|c|c|c|c|c|c|}
\hline \multirow[b]{2}{*}{ Component } & \multirow[b]{2}{*}{ Series } & \multicolumn{4}{|c|}{ Percentage point contribution to year-over-year change } \\
\hline & & Dec. 2019 & Dec. 2021 & Dec. 2022 (forecast) & $\begin{array}{l}\text { Dec. } 2023 \text { (forecast) } \\
\end{array}$ \\
\hline \multicolumn{6}{|l|}{ Housing } \\
\hline & CPI Services & 1.7 & 1.9 & 3.4 & 2.7 \\
\hline & Core CPI & 1.3 & 1.5 & 2.6 & 2.1 \\
\hline & Headline CPI & 1.1 & 1.1 & 2.1 & 1.6 \\
\hline \multicolumn{6}{|l|}{ Housing } \\
\hline & PCE Services & 0.8 & 0.8 & 1.5 & 1.2 \\
\hline & Core PCE & 0.6 & 0.6 & 1.1 & 0.9 \\
\hline & Headline PCE & 0.5 & 0.6 & 1.0 & 0.8 \\
\hline
\end{tabular}

Sources: Bureau of Labor Statistics. Bureau of Economic Analysis, Authors' calculations.

Notes: Weights are 2020 vintage for CPI comparability with reported Dec. 2021 rates. For both PCE and CPI, housing only includes owners' equivalent rent and rent of primary residence/rental of tenant-occupied non farm housing.

\section{Figure 4: Contributions of Housing to Core Inflation}

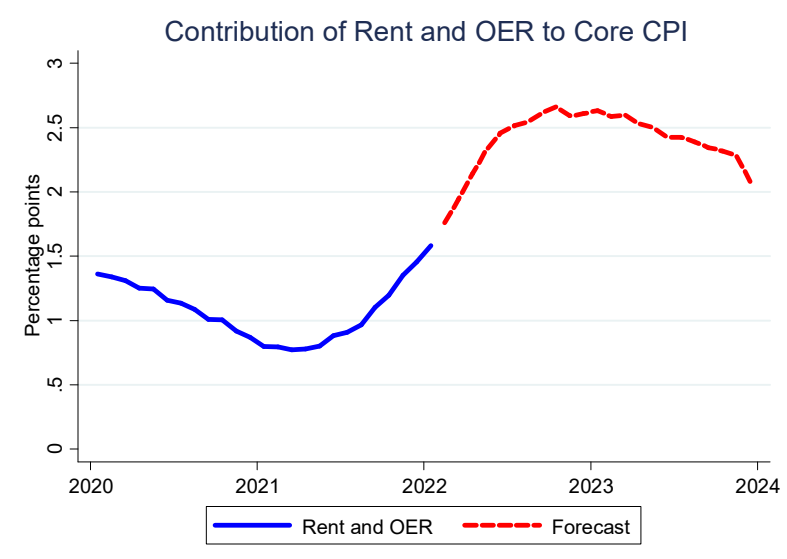

(a)

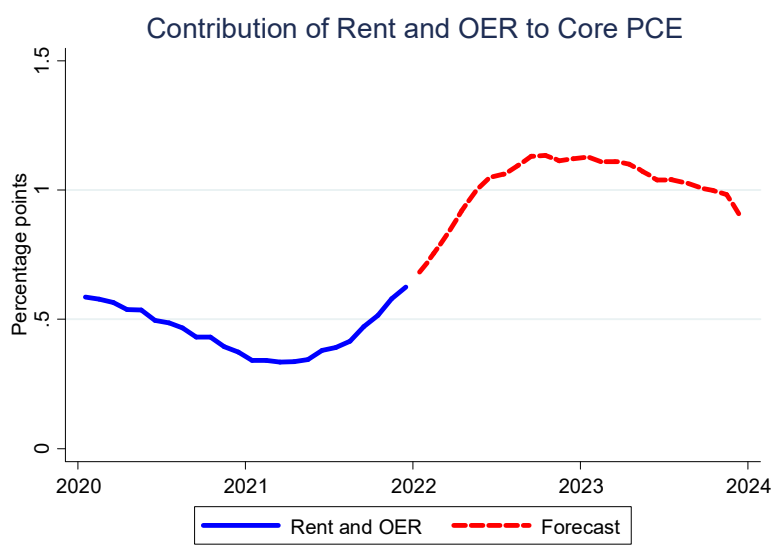

(b)

Sources: Bureau of Labor Statistics. Private sector rent data from CoreLogic Single-Family Rent Index. Home prices from Zillow Home Value Index. Authors' calculations.

Notes: Panel (a) plots the combined contribution of rent and OER to core CPI. Panel (b) plots the combined contribution of rent and OER to core PCE. See Table 1 for weights. 


\section{Headline and core inflation under different scenarios}

It is clear from our forecasts that the contribution of housing to inflation will be substantial in 2022. We now assess the overall impact on core and headline inflation under two scenarios, the results of which are available upon request. First, even if the rest of the CPI basket returns to the target of two percent, we project that housing will push up core CPI to 3.8 percent in December 2022, and headline CPI to 3.4 percent. The effect of housing on PCE is less dramatic, but our forecasts imply that core and headline PCE would still be 80 and 70 basis points above target respectively if the rest of the PCE basket returns to two percent.

Second, much has been made of the unprecedented run-up in used car and truck prices in 2021, which contributed around one percentage point to core and headline inflation. This component receives a weight of between 1.6 and 5.2 percent in the different indices. We estimate that even if the price of used cars relative to the overall CPI returns to pre-pandemic levels, this would not offset the additional residential services inflation that we project in 2022.

\section{Robustness checks}

Additional exercises estimating OER and rent for the CPI suggest that our estimates are robust due to their stability irrespective of data series choices or forecasting techniques. For all robustness checks, the forecasts of rent and OER in December 2022 imply a substantial increase in the contribution of housing to overall inflation in 2022. We summarize these exercises in the Appendix. First, rather than forecasting using separate models for each month in 2022, we estimate models for rent and OER one month ahead and simulate a path for the rest of the year. Our forecasts are very similar to baseline, with the combined inflation rate of OER and rent amounting to 6.8 percent in December 2022. 
As a second robustness check, we include Zillow's Home Value Forecast (ZHVF) for 2022 as a predictor. Zillow recently revised the ZHVF up to 16.4 percent in December 2022. In this case, our forecasts for rent are almost identical to the baseline and the OER forecast increases slightly.

Third, we set up a model that only uses home prices as leading indicators for rent and OER. Dropping private sector rent data allows us to extend the sample back to 1987. For home prices, we employ the S\&P/Case-Shiller Index which has longer coverage. In this case, the model forecasts an increase of 4.8 percent in the housing component of the CPI in late 2022. Although this forecast is lower than the baseline model, it is still elevated relative to current levels. The difference arises because the elasticity of rent and OER with respect to home prices was considerably lower in the 1990s than in the previous two decades. The forecasts of this version of the model are similar to the baseline if we restrict the sample to the post-2004 period.

Finally, we include leading indicators for new homes that may affect rent and OER by increasing supply. We use monthly data on new privately-owned housing units under construction and new building permits issued from the Census Bureau and the Department of Housing and Urban Development. With the additional indicators, the model projects eight percent for the weighted inflation rate of OER and rent in the CPI in December 2022. This increase in our forecasts reflects the muted supply response relative to what would have been predicted given historical relationships and the rapid run-up in housing prices since the start of the pandemic.

\section{The Supply Response}

New home starts stood at a seasonally adjusted annual rate of 1.7 million homes in January 2022. This is near the highest levels since the pandemic started, but it is far short of the rate needed to 
return the housing market to normal footing. As of the fourth quarter of 2020, Freddie Mac estimated that there was a shortage of 3.8 million units in the US (Khater et al, 2021). Since then, the situation has only gotten worse- both rental and ownership vacancies were at their lowest recorded levels in January 2022, far below the rates estimated for a well-functioning housing market. Covid-induced supply bottlenecks, in concert with a shortage of available land and zoning restrictions have all exacerbated the mismatch between where people want to live and the prices that many can pay. Recent statements from one of the largest homebuilders suggest that the bottlenecks are not yet abating (Weisenthal, 2022). New home supply is relatively easy to predict due to the lags between lot purchase, building permit, and coming to market. Our models suggest that the growth in new supply will moderate in 2022, keeping the supply of new homes for sale below the peak of the previous cycle. 


\section{Section 5: Conclusion}

In the era of Covid, extrapolating from historical relationships comes with substantial uncertainty. This is especially true for residential services, as work from home, changes in household formation, and supply bottlenecks have affected both sides of the housing and rental markets. We take this opportunity to list a few other caveats that could serve to bias our forecasts.

Especially for continuing tenants, there are varying state and local laws that cap rent increases. ${ }^{20}$ While these restrictions do not always bind in all jurisdictions, they could attenuate our results as landlords may not be able to adjust to the spot price as quickly as they have in the past. Newly proposed and existing laws on rent control and eviction moratoria would also make our estimates for 2022 too high. Additionally, while we do not think that bottlenecks were the sole reason for cost increases, their easing could lead to a strong supply response. If there are nonlinearities in the response of construction to prices - as prices have risen at record rates - then prices may decline faster than the data on which our forecasting models are trained. ${ }^{21}$ On the other hand, if bottlenecks continue well into 2022, our estimates might be biased downwards as the lack of new supply could exacerbate strong rental price growth. In the same direction, strong housing pricing growth could price potential new homebuyers out of the housing market and keep them in the rental market. This could serve to strengthen the rental market beyond our estimates and lead to higher measured residential services inflation than we project. Taking a step back, our model itself is calibrated on past readings for private sector home and rental increases that are not as large as they are currently. Continuing unprecedented price rises could also make our extrapolation more error prone in either direction.

\footnotetext{
${ }^{20}$ See Been et al. (2019) for a recent discussion of the past, present, and possible futures of rent regulations.
} 
Despite these caveats, using a variety of techniques and datasets, we estimate housing's contribution to 2022 inflation as almost incompatible with a swift return to trend inflation. The way that housing inflation is measured—as the average price growth across all housing occupants, not as the average price increase one looking for housing today would pay relative to an earlier period — ensures that past developments in the housing market will result in an increase in recorded housing inflation in 2022. Our findings suggest that if past relationships hold into 2022, housing inflation is likely to move to between 6.5 percent and seven percent and make a significant contribution to overall inflation in 2022 , ranging from one to nearly three percentage points. Although our projections suggest that residential inflation will peak in late 2022, we expect it to remain elevated in 2023. 


\section{References}

Ambrose, Brent W., N. Edward Coulson, and Jiro Yoshida. "The repeat rent index." Review of Economics and Statistics 97.5. (2015).

Bai, J., \& Ng, S. "Forecasting economic time series using targeted predictors." Journal of Econometrics, 146(2), 304-317. (2008).

Been, Vicki, Ingrid Gould Ellen, and Sophia House. "Laboratories of regulation: understanding the diversity of rent regulation laws." Fordham Urb. LJ 46. (2019).

Bernstein, Jared, Ernie Tedeschi, and Sarah Robinson. "Housing prices and inflation." The Council of Economic Advisers Blog Post. (2021).

Blair, Caitlin. "Constructing a PCE-weighted consumer price index." Vol. 74. University of Chicago Press. (2015).

Brescia, Eric. "Housing poised to be strong driver of inflation" Fannie Mae Housing Insights. (2021).

Cepni, O., Güney, I. E., \& Swanson, N. R. "Nowcasting and forecasting GDP in emerging markets using global financial and macroeconomic diffusion indexes." International Journal of Forecasting, 35(2), 555-572. (2019).

De Silver, Drew. "As national eviction ban expires, a look at who rents and who owns in the U.S.” Pew Research Center Blogpost. (2021).

Dolmas, Jim, and Xiaoqing Zhou. "Surging House Prices Expected to Propel Rent Increases, Push Up Inflation." Federal Reserve Bank of Dallas Blogpost. (2021).

Eickmeier, S., \& Ng, T. "Forecasting national activity using lots of international predictors: An application to New Zealand." International Journal of Forecasting, 27(2), 496-511. (2011).

Garner, Thesia I., George Janini, William Passero, Laura Paszkiewicz, and Mark Vendemia. "The CE and the PCE: A Comparison." Monthly Labor Review. (2006).

Gindelsky, Marina, Jeremy Moulton, and Scott A. Wentland. "Valuing housing services in the era of big data: A user cost approach leveraging Zillow microdata." Big Data for $21^{s t}$ Century Economic Statistics. (2019)

Glaeser, Edward L. and Joseph Gyourko. "Arbitrage in Housing Markets," in E. L. Glaeser and John M. Quigley editors, Housing markets and the economy: risk, regulation, and policy: essays in honor of Karl E. Case. (2009). 
Hoerl, A. E., and Kennard, R. W. "Ridge regression: Biased estimation for nonorthogonal problems." Technometrics, 12(1), 55-67. (1970).

Johnson, Noah. "A comparison of PCE and CPI: Methodological Differences in US Inflation Calculation and their Implications November 2017." (2017).

Khater, Sam., Len Kiefer, and Venkataramana Yanamandra. "Housing Supply: A Growing Deficit." Freddie Mac Housing and Research Note. (2021).

McCully, Clinton P., Brian C. Moyer, and Kenneth J. Stewart. "Comparing the consumer price index and the personal consumption expenditures price index." Survey of Current Business 87.11 (2007).

Passero, William, Thesia I. Garner, and Clinton McCully. "Understanding the relationship: CE survey and PCE." Improving the measurement of consumer expenditures. (2014.)

Rassier, Dylan G., Bettina H. Aten, Eric B. Figueroa, Solomon Kublashvili, Brian J. Smith, and Jack York. "Improved Measures of Housing Services for the U.S. Economic Accounts." Survey of Current Business. (2021).

Shelton, John P. "The cost of renting versus owning a home." Land Economics 44.1. (1968).

Stock, J. H., \& Watson, M. Dynamic factor models. Oxford Handbooks Online. (2011).

Tibshirani, R. Regression shrinkage and selection via the lasso. Journal of the Royal Statistical Society: Series B (Methodological), 58(1), 267-288. (1996).

US Department of Labor Staff, and United States Bureau of Labor Statistics. BLS handbook of methods. (2018).

Verbrugge, Randal J. "The puzzling divergence of rents and user costs, 1980-2004," Review of Income and Wealth, 54(4). (2008).

Weisenthal, Joe. "A Major Homebuilder Sees No Improvement Coming to the Supply Chain in 2022." Bloomberg News. (2022).

Zou, H., \& Hastie, T. "Regularization and variable selection via the elastic net." Journal of the royal statistical society: series B (statistical methodology), 67(2), 301-320. (2005). 


\section{Appendix}

Table A.1: Monthly Forecasts

\begin{tabular}{|c|c|c|c|c|}
\hline \multirow[t]{2}{*}{ Month } & \multicolumn{2}{|l|}{ CPI } & \multicolumn{2}{|l|}{ PCE } \\
\hline & OER & Rent & OER & Rent \\
\hline Jan. 2022 & - & - & 4.1 & 3.8 \\
\hline Feb. 2022 & 4.5 & 4.2 & 4.5 & 4.2 \\
\hline Mar. 2022 & 4.9 & 4.8 & 4.9 & 4.8 \\
\hline Apr. 2022 & 5.5 & 5.3 & 5.4 & 5.3 \\
\hline May. 2022 & 5.9 & 5.8 & 5.9 & 5.8 \\
\hline Jun. 2022 & 6.2 & 6.2 & 6.2 & 6.0 \\
\hline Jul. 2022 & 6.3 & 6.5 & 6.1 & 6.6 \\
\hline Aug. 2022 & 6.3 & 6.8 & 6.4 & 6.7 \\
\hline Sep. 2022 & 6.5 & 7.0 & 6.5 & 7.0 \\
\hline Oct. 2022 & 6.6 & 7.2 & 6.6 & 7.1 \\
\hline Nov. 2022 & 6.3 & 7.3 & 6.3 & 7.2 \\
\hline Dec. 2022 & 6.3 & 7.4 & 6.4 & 7.3 \\
\hline Jan. 2023 & 6.5 & 7.3 & 6.5 & 7.3 \\
\hline Feb. 2023 & 6.4 & 7.1 & 6.4 & 7.1 \\
\hline Mar. 2023 & 6.4 & 7.1 & 6.4 & 7.1 \\
\hline Apr. 2023 & 6.3 & 6.8 & 6.3 & 7.0 \\
\hline Мау. 2023 & 6.2 & 6.7 & 6.2 & 6.8 \\
\hline Jun. 2023 & 6.0 & 6.4 & 6.0 & 6.4 \\
\hline Jul. 2023 & 6.0 & 6.7 & 5.9 & 6.7 \\
\hline Aug. 2023 & 5.9 & 6.6 & 5.9 & 6.7 \\
\hline Sep. 2023 & 5.8 & 6.5 & 5.8 & 6.5 \\
\hline Oct. 2023 & 5.7 & 6.4 & 5.7 & 6.4 \\
\hline Nov. 2023 & 5.6 & 6.3 & 5.6 & 6.3 \\
\hline Dec. 2023 & 5.0 & 6.0 & 5.1 & 6.0 \\
\hline
\end{tabular}

Notes: See text for details. 
Figure A.1: Out-of-sample performance for one year forecast (OER CPI)

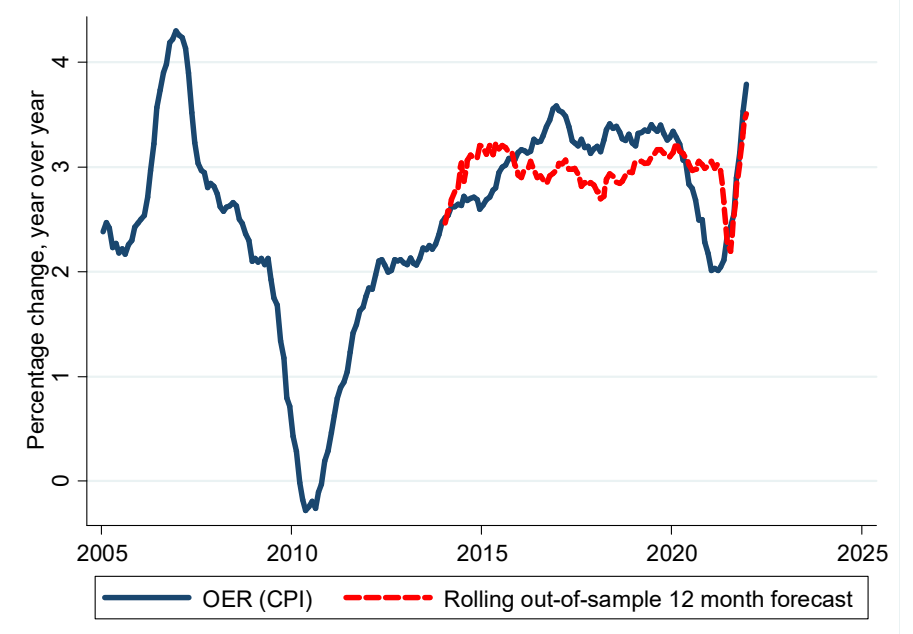

Sources: Bureau of Labor Statistics. Private sector rent data from CoreLogic Single-Family Rent Index. Home prices from Zillow Home Value Index. Authors' calculations.

Notes: Forecast model is an elastic net using 24 months of lags in the year-over-year growth rates of the dependent variable and 24 months of lags in the year-over-year growth rate of the Zillow Home Value Index and the CoreLogic Single-Family Rent Index. 
Table A.2: Robustness Checks

\begin{tabular}{|c|c|c|c|c|}
\hline Series & Model and data & Component & $\begin{array}{l}\text { Forecast Dec. } 2022 \\
(\% \text { y-0-y) }\end{array}$ & $\begin{array}{l}\text { Forecast Dec. } 2023 \\
(\% \text { y-o-y) }\end{array}$ \\
\hline \multirow[t]{15}{*}{ Core CPI } & \multirow{3}{*}{ Baseline } & OER & 6.3 & 5.0 \\
\hline & & Rent & 7.4 & 6.0 \\
\hline & & Housing & 6.6 & 5.3 \\
\hline & \multirow{3}{*}{ Simulate path } & OER & 6.6 & 5.1 \\
\hline & & Rent & 7.4 & 4.8 \\
\hline & & Housing & 6.8 & 5.0 \\
\hline & \multirow{3}{*}{$\begin{array}{l}\text { Use Zillow home } \\
\text { price forecast }\end{array}$} & OER & 6.5 & 5.3 \\
\hline & & Rent & 7.4 & 6.0 \\
\hline & & Housing & 6.7 & 5.5 \\
\hline & \multirow{3}{*}{$\begin{array}{l}\text { Home prices } \\
\text { only from } 1987 \\
\text { onwards }\end{array}$} & OER & 4.8 & 4.8 \\
\hline & & Rent & 5.0 & 5.3 \\
\hline & & Housing & 4.8 & 4.9 \\
\hline & \multirow{3}{*}{$\begin{array}{l}\text { Add supply } \\
\text { indicators to } \\
\text { model }\end{array}$} & OER & 7.0 & 4.2 \\
\hline & & Rent & 11.2 & 5.1 \\
\hline & & Housing & 8.0 & 4.4 \\
\hline
\end{tabular}

Notes: See text for details. 
Figure A.2: Forecast model includes simulated path of dependent variable (CPI)
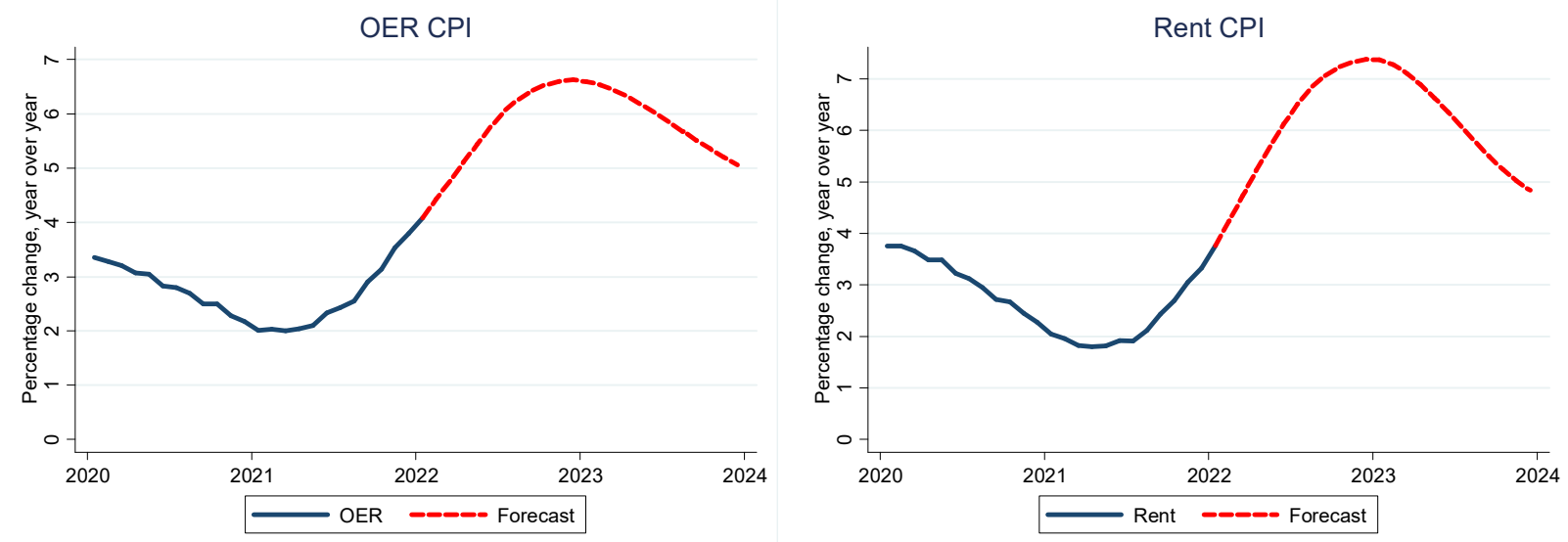

Notes: See text for details.

Figure A.3: Forecast model includes Zillow home price forecast for 2022 (CPI)
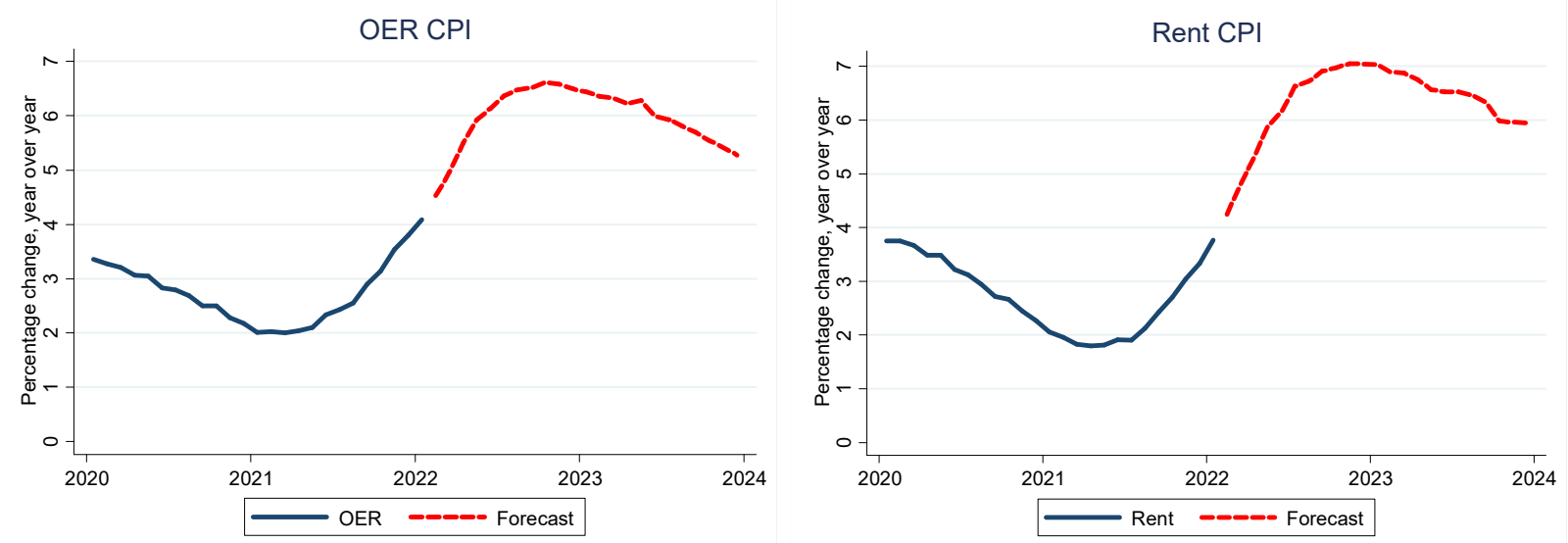

Notes: See text for details. 
Figure A.4: Forecast model uses only S\&P/Case-Shiller Index (CPI)
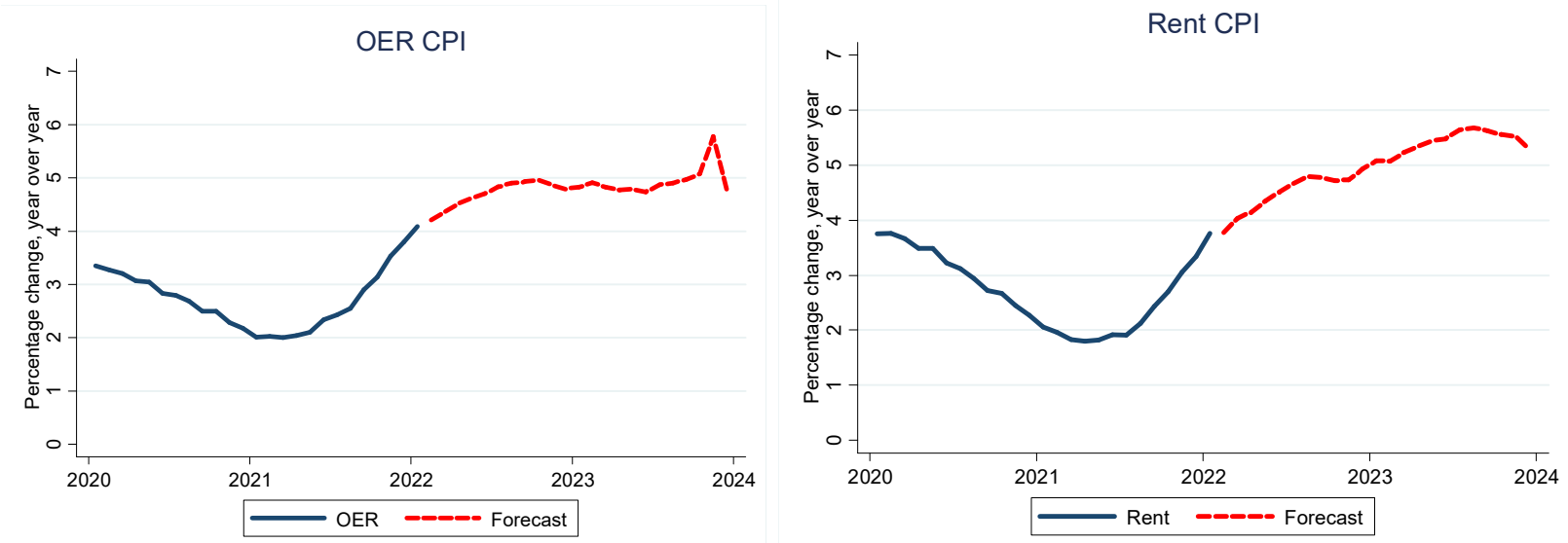

Notes: See text for details.

Figure A.5: Forecast model includes supply indicators (CPI)
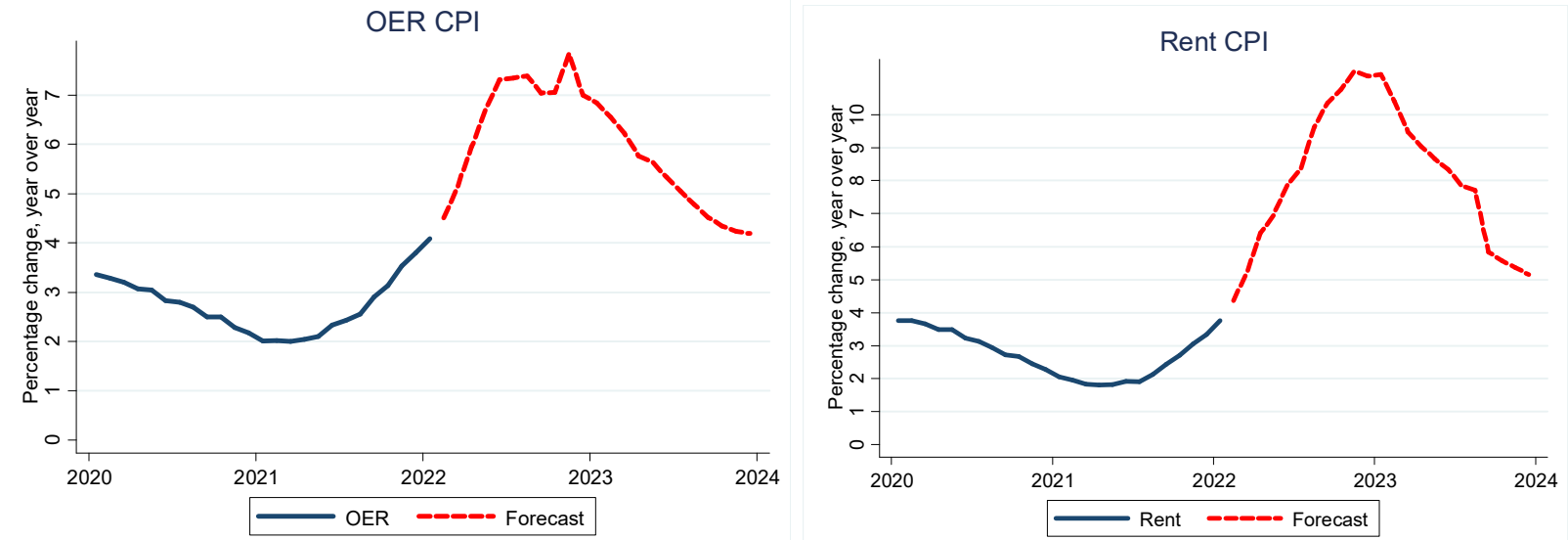

Notes: See text for details. 